\title{
Low-cost multispecies air quality sensor
}

\author{
C. M. Wang, B. D. Esse \& A. C. Lewis \\ University of York, UK
}

\begin{abstract}
Field measurements of volatile organic compounds (VOCs) are important in a range of disciplines including air pollution science, medical diagnostics and security screening. There is an enduring need for portable devices that provide reliable compound-specific measurements, at mixing ratios in the part per billion and part per trillion ranges. Such devices should ideally be robust, low-cost and have low-power demands. This work describes the development of a lab-on-a-chip (LOC) device for VOC measurements, a collaboration of multiple disciplines, involving research and development from a number of different fields in sciences and engineering. Such a collaborative approach is necessary for the assembly and integration of sample collection and preparation stages, gas chromatography (GC) separation and photoionisation detection (PID), to create a complete functional system. The objective of this project is to develop a multispecies sensor for measuring hydrocarbons and oxygenated compounds in gas phase samples, through the deployment of thermal desorption methods in combination with a micro-fabricated GC-PID device. The final developed system will allow measurements of a range of different organic compounds in air. This will be validated using controlled experiments and against reference standards and measurement techniques. The system will be applied in number of real-world monitoring investigations, including indoor atmospheres and air pollution studies. In this paper we describe progress towards development of a low power GC chip temperature control system and a low cost PID detector suitable for microfabricated GC.
\end{abstract}

Keywords: volatile organic compounds, lab-on-a-chip, microfabrication, gas chromatography, photoionisation detection, field instrumentation. 


\section{Introduction}

Volatile organic compounds (VOCs) are organic compounds with boiling points of less than or equal to $250^{\circ} \mathrm{C}$ measured at a standard atmospheric pressure of $101.3 \mathrm{kPa}$ [1]. These compounds can have both direct and indirect impacts on human health. VOCs are emitted from natural and anthropogenic (man-made) sources. Some natural sources of VOCs include vegetation, forest fires, and animals and these dominate the global budget of emissions. Although on a global scale VOC emissions are largely from natural sources, air quality problems in populated and industrialized areas are mainly a result of anthropogenic sources [2]. Some examples of anthropogenic VOCs include tobacco smoke, biomass burning from human activities i.e. to exploit land for agricultural activities or to rid of agricultural waste, the production, storage and use of fossil fuels, and the production and use of household chemicals such as cleaning agents, coatings and paints.

VOCs contribute to the production of ozone, a constituent of photochemical smog that causes adverse health problems and also, when degraded in air, to the formation of organic aerosols. Ozone is formed in the atmosphere via a photochemical process whereby VOCs react with hydroxyl radicals in the presence of sunlight forming short-lived peroxy radical species $\left(\mathrm{RO}_{2}\right) \cdot \mathrm{RO}_{2}$ can then react further rapidly converting $\mathrm{NO}$ to $\mathrm{NO}_{2}$, perturbing the natural photostationary state. Photolysis the $\mathrm{NO}_{2}$ formed then induces additional ozone formation. Thus ground level ozone is as a secondary pollutant and a harmful photochemical oxidant which inhabits that troposphere and it is the main component of photochemical smog [3].

Ozone can be produced from simple hydrocarbons such as ethane, propane or from oxygenated compounds like formaldehyde and acetaldehyde. In indoor microenvironments and urban air, formaldehyde mixing ratios can vary from 1 to $100 \mathrm{ppb}$, while in remote clean oceanic areas formaldehyde is generally in the range $0.1-1.0 \mathrm{ppb}$ [4]. Ethane and propane originate substantially from anthropogenic pollution sources and have relatively long lifetimes against photochemical destruction. Background tropospheric mixing ratios of ethane and propane are $0.3-2.5 \mathrm{ppbv}$ and $0.01-1.0 \mathrm{ppbv}$ respectively. In addition to the production of ozone, acetaldehyde is also a precursor to peroxyacetyl nitrate (PAN), a secondary pollutant found in photochemical smog. It is a lachrymator and causes eye irritation. It has been reported that mixing ratios of PAN in clean air are typically $2-100 \mathrm{pptv}$, whereas that of polluted air can be as high as $35 \mathrm{ppbv}$ [5]. The rapid and sensitive measurements of VOCs in ambient and indoor environments are therefore of great utility to environmental toxicology and atmospheric chemistry.

For the field measurement of VOCs, there is a need for a portable device that provides reliable information on a range of different VOCs, since the impact on downstream effects such as ozone and aerosol formation and health toxicology are structure-specific. Bulk measurements (e.g. total carbon mass per unit volume) of VOCs do not provide sufficient detail on the types of VOC present to be useful in most environmental and health applications. Any portable device should be robust, 
low-cost and have low-power demands, since many applications are likely to be off-grid. The development of a Lab-on-a-Chip (LOC) device requires a collaboration of multiple disciplines, involving research and development from different fields in sciences and engineering. This is necessary for the assembling and integration of the different components involved in a LOC to create a complete functional system.

\subsection{Current measurement methods}

There are numerous techniques and instruments used for the detection and measurement of VOCs, mostly based around gas chromatography and mass spectrometry. Some examples of are summarised in Table 1, together with the respective trade-offs of each method for field analysis. In very general terms, the development of VOC instrument starts with laboratory standard devices, such as GC and MS, with modifications and additions then made to accommodate a trace level gaseous sample matrix. The key front-end adaptation to all chromatography-based systems is the inclusion of a thermal pre-concentration step, which strips VOCs from litre volumes of air and introduces them to the GC column with a concentration factor of up to 1000. A consequence is that most instruments in the literature for VOC detection are essentially hybrid lab instruments, not devices intrinsically designed with size, power or weight as constraining factors.

In view of the mentioned limitations of current technologies for field analysis of VOCs, this work aims to address these issues and develop a portable sensor for the detection and analysis of VOCs, combining elements of thermal desorption, gas chromatography and PID, but in device built bottom up, rather than from standard lab equipment.

\section{Preliminary design of the GC-LOC}

The simple design for a GC-LOC column arrangement is as shown in Figure 1. The device is etched in a planar form which facilitates heating of the GC-LOC with a Peltier thermoelectric device [19], rather than the much higher power of a standard turbulent fan oven. A secondary advantage of a Peltier controlled device is an ability to operate below ambient temperatures, something not achievable in a fan oven without cryogenic cooling. The chip design is formatted to the same shape as existing Peltier devices commonly available at low cost. The design here uses two wafers, with etched channels on one side, bonded together to form a single chip. A number of different materials can be potentially used including glass, acrylic and PDMS. Prototyping using PDMS provides a quick and costefficient way of testing the feasibility of the GC-LOC design and is the initial route taken. The $45 \times 45 \mathrm{~mm}$ chip will have an etch depth of a $150 \mu \mathrm{m}$ semi-circle on one side. Etches will be spaced $100 \mu \mathrm{m}$ apart and the capillary has a total length of about $4 \mathrm{~m}$. 
Table 1: Current measurement methods for VOCs.

\begin{tabular}{|c|c|c|}
\hline $\begin{array}{l}\text { Current measurement } \\
\text { methods and its } \\
\text { characteristics }\end{array}$ & Pros & Cons \\
\hline $\begin{array}{l}\text { Thermal desorption - Gas } \\
\text { Chromatography with } \\
\text { Flame Ionisation Detectors } \\
\text { (FID) }\end{array}$ & $\begin{array}{l}\text { - Very sensitive and linear in } \\
\text { response. } \\
\text { - Good in serviced laboratories } \\
\text { or for fixed site observatories. } \\
\text { - Stable and reliable when } \\
\text { operated autonomously. }\end{array}$ & $\begin{array}{l}\text { - Not selective: respond to all } \\
\text { organic compounds (except } \\
\text { HCHO). Issues due to co- } \\
\text { elutions; unable to identify } \\
\text { unknown compounds. } \\
\text { - Not portable due to its size, } \\
\text { mass and } \mathrm{H}_{2} \text { requirement. }\end{array}$ \\
\hline $\begin{array}{l}\text { Bulk Photo-Ionisation } \\
\text { Detection (PID) }\end{array}$ & $\begin{array}{l}\text { - Portable detector suitable for } \\
\text { field applications because of its } \\
\text { small size and no need for } \\
\text { supply gases. } \\
\text { - The trade-off between using } \\
\text { the PID or the FID in detection } \\
\text { of VOCs has been discussed } \\
\text { [6]; the FID gave better } \\
\text { resolved peaks compared to the } \\
\text { PID. However, the PID is } \\
\text { portable has much lower power } \\
\text { demands. }\end{array}$ & $\begin{array}{l}\text { - Operated in isolation the PID is } \\
\text { not selective: will respond to all } \\
\text { organic compounds. } \\
\text { - Each VOC has a different } \\
\text { ionisation potential, which } \\
\text { requires calibration. }\end{array}$ \\
\hline $\begin{array}{l}\text { Proton-Transfer-Reaction } \\
\text { Mass Spectrometry (PTR- } \\
\text { MS) }\end{array}$ & $\begin{array}{l}\text { - Allows numerous VOCs of } \\
\text { atmospheric interest to be } \\
\text { monitored with a high } \\
\text { sensitivity }(10-100 \mathrm{pptv}) \text { and } \\
\text { rapid response time }(1-10 \mathrm{sec}) \text {. } \\
\text { - Does not require any sample } \\
\text { treatment such as drying or } \\
\text { pre-concentration, and is thus } \\
\text { well suited for oxygenated } \\
\text { VOCs. } \\
\text { - Provides a fast-response } \\
\text { measurement of several key } \\
\text { atmospheric VOCs. }\end{array}$ & $\begin{array}{l}\text { - Only determines the mass of } \\
\text { product ions, which is not a } \\
\text { unique indicator of the VOC } \\
\text { identity. } \\
\text { - Isomers cannot be } \\
\text { distinguished, and the } \\
\text { interpretation of mass spectra is } \\
\text { further complicated by cluster } \\
\text { ions formation and product ions } \\
\text { fragmentation. } \\
\text { - Not easily portable for field } \\
\text { measurements. } \\
\text { - 200K-400K USD hardware } \\
\text { costs. }\end{array}$ \\
\hline $\begin{array}{l}\text { Thermal Desorption } \\
\text { GC-MS }\end{array}$ & $\begin{array}{l}\text { - Sensitive and accurate means } \\
\text { of retrospective analysis of } \\
\text { VOCs adsorbed in soil samples } \\
{[8,9], \text { other solids }[10,11] \text {, }} \\
\text { liquids }[12,13] \text { and gases } \\
{[14-16] .} \\
\text { - Sensitive and flexible, } \\
\text { compound identifications } \\
\text { available from mass spectra. } \\
\text { - Capable of identifying } \\
\text { unknown compounds in an air } \\
\text { sample via MS libraries. } \\
\text { - More sensitive from similar } \\
\text { FID systems if operated in } \\
\text { selected ion modes. }\end{array}$ & $\begin{array}{l}\text { - Size and mass of the bench-top } \\
\text { instrumentation render this } \\
\text { method unsuitable for field } \\
\text { analysis. } \\
\text { - More challenging to calibrate } \\
\text { and less stable when operated } \\
\text { continuously. } \\
\text { - Water can be a significant } \\
\text { interference. } \\
\text { - Higher cost, more complex and } \\
\text { typically requires thermostated } \\
\text { lab environment for optimal } \\
\text { operation. } \\
\text { - Several kilowatt power } \\
\text { requirement. }\end{array}$ \\
\hline
\end{tabular}


Table 1 Continued.

\begin{tabular}{|c|c|c|}
\hline $\begin{array}{l}\text { Current measurement } \\
\text { methods and its } \\
\text { characteristics }\end{array}$ & Pros & Cons \\
\hline $\begin{array}{l}\text { Colorimetric ("Stain") } \\
\text { tubes i.e. Draeger tubes }\end{array}$ & $\begin{array}{l}\text { - Inexpensive method of } \\
\text { measuring classes of toxic } \\
\text { gases and vapours. }\end{array}$ & $\begin{array}{l}\text { - Continuous observations } \\
\text { needed to ensure no sudden } \\
\text { complete discoloration. } \\
\text { - Ultra-violet radiation may result } \\
\text { in a change in the discoloration } \\
\text { [17]. } \\
\text { - Readings in the form of colour } \\
\text { changes and intensities are } \\
\text { subjected to human } \\
\text { interpretation. } \\
\text { - Not VOC specific. }\end{array}$ \\
\hline $\begin{array}{l}\text { Metal Oxide } \\
\text { Semiconductor (MOS) } \\
\text { sensors }\end{array}$ & $\begin{array}{l}\text { - Compact and low cost sensors } \\
\text { with high sensitivity and short } \\
\text { response time. }\end{array}$ & $\begin{array}{l}\text { - Also respond to inorganic gases } \\
\text { [18]: problem when trying to } \\
\text { measure trace or low } \\
\text { concentrations of VOCs in the } \\
\text { presence of gases such as NO, } \\
\mathrm{NO}_{2} \text { or } \mathrm{CO} \text { which are found in } \\
\text { the surrounding air. } \\
\text { - Not favourable in the field } \\
\text { measurement of VOCs because } \\
\text { of the lack of selectivity and } \\
\text { control of the sensor response. }\end{array}$ \\
\hline
\end{tabular}

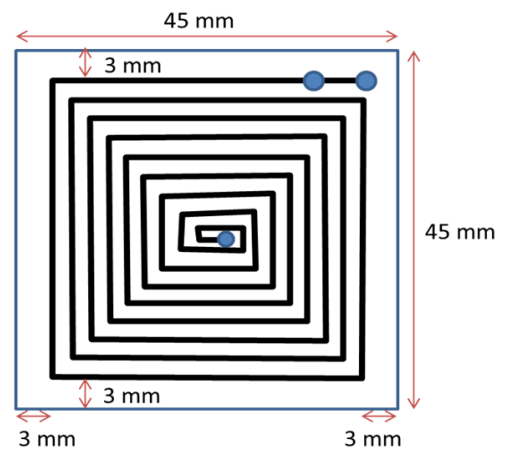

Figure 1: Preliminary design of GC-LOC on square-shaped chip.

\section{Heating of the GC column}

One important factor for an effective GC separation is the uniform heating of the GC column and the ability to increase this temperature linearly to elute higher boiling compounds sequentially. The heating of GC columns by conventional means is primarily based on the turbulent fan oven, which is an excellent means to achieve even heating of the column. However the size of such ovens renders this a difficult technique to use in remote locations for field analysis in 
environmental research, and the power consumption is of the order $1.5 \mathrm{~kW}$ for a typical $10^{\circ} \mathrm{C} \mathrm{min}^{-1}$ heating rate. The fabrication of a GC-LOC described above allows a structural geometry that is much easier to heat using planar devices, such as a Peltier device which could be placed on the surface of the fabricated chip. In addition, the Peltier device allows the starting temperature to be below room temperature, allowing the improved separation of volatile VOCs without the need for cryogenic cooling, as used in standard GC ovens. To mimic the temperature control we have of in existing GC ovens, it is essential that the temperature gradients and set points of the Peltier device can be manipulated to allow manual control of the device.

\subsection{Temperature control of the Peltier device}

A program is designed using LABVIEW to control the temperature (set points and gradients) of a Peltier device. We have estimated that a functional working range of temperature should be from $10^{\circ} \mathrm{C}$ to $100^{\circ} \mathrm{C}$, which broadly mimics in terms of peak capacities a standard separation of VOCs performed over $40-150^{\circ} \mathrm{C}$. The Peltier device is used as both a heater and a cooler in this device, with a switch over between cooling and heating achieved via a polarity reversal in the d.c. supply. The control software essentially mimics a standard GC bringing the temperature of the device to an initial value $\left(10^{\circ} \mathrm{C}\right)$, holding it there, and then ramping the temperature at a given rate $\left(10^{\circ} \mathrm{C} \mathrm{min}^{-1}\right)$ until the final temperature is reached $\left(100^{\circ} \mathrm{C}\right)$ before cooling back down to $30^{\circ} \mathrm{C}$. This is achieved through Proportional Integral Derivative control. Figure 2 shows the result of the one temperature cycle test. The program produces a desired set point temperature profile (blue graph) and adjusts the power supplied to the Peltier device to bring the temperature of the device (red graph) to this value. The Peltier device is fitted with a heat sink and fan as it requires cooling.

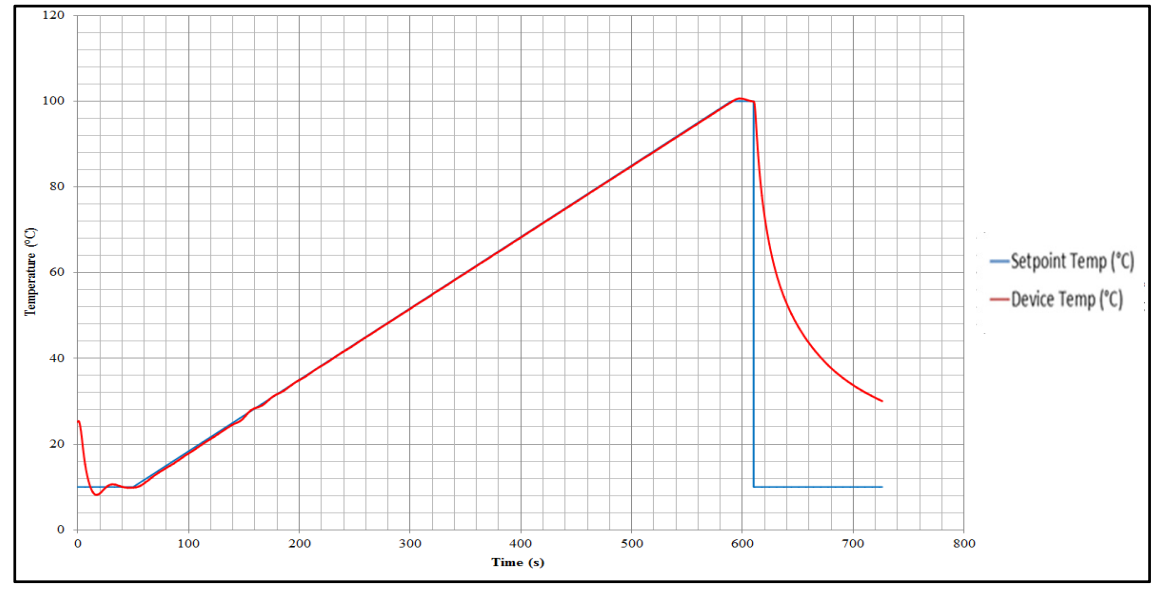

Figure 2: $\quad$ One temperature cycle of the Peltier device. 
To test the performance of the Peltier device for continuous sequential runs, five of such temperature cycles were set to run and the resulting temperature profiles are shown in the Figure 3. It was noted that the set point and device temperatures were almost identical for the majority of each ramp and that there was no thermal wind-up in the system - that is the starting $10^{\circ} \mathrm{C}$ could be achieved reproducibility each time.

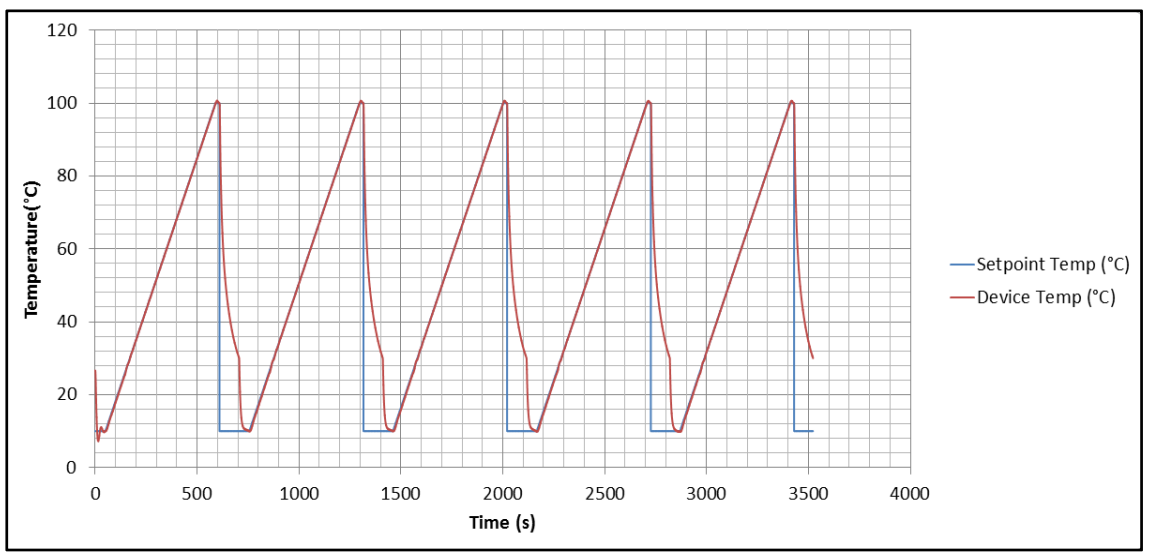

Figure 3: Five cycles of the Peltier device used for GC chip temperature control.

Features of note are the slight overshoot at the initial and final temperatures, and the slight wobble through room temperature region as the voltage polarities are reversed. These can be optimised for a set of conditions, however in significantly different ambient conditions the Proportional Integral Derivative gains may need to be re-tuned if these differences to the set point become too large. As it is, the discrepancies are never more than about $1{ }^{\circ} \mathrm{C}$ (except the initial overshoot, which is often around $2^{\circ} \mathrm{C}$ ).

The total power used in this set up is about $40 \mathrm{~W}$, which relates to about $24 \mathrm{~kJ}$ per cycle of 10 minutes. This is a considerably lower power consumption compared to a laboratory gas chromatography oven which uses on average $1 \mathrm{~kW}$ over 30 minutes - that is, $1.8 \mathrm{MJ}$ per cycle.

\section{Separation performance in a laboratory GC with PID}

A key barrier to portable GC systems has been a lack of suitable detector for the field. The most simple lab detector is FID, but that is orientation specific and requires a hydrogen supply. Here we have focused attention on a low-cost ( 200 USD), commercially available PID (PID-AH, Alphasense) as the detection method for VOCs measurement following GC. The PID used here is designed primarily for a solvent alarm, not a GC detector, so we have undertaken experiments to understand its capabilities if modified for this purpose. The ultraviolet lamp of the PID provided $10.6 \mathrm{eV}$ for compound ionisation and the 
device was used as supplied, with the exception of the deliberate removal of a filter inlet placed over the detection grids. High purity helium (BIP Air Products, Keumiee, Belgium) was used as the carrier gas for GC. Separation was performed on a BPX5 column $(50 \mathrm{~m} \times 0.32 \mathrm{~mm} \times 1.0 \mu \mathrm{m}$, length $\mathrm{x}$ internal diameter $\mathrm{x}$ film thickness) with two split outlets, one going to a time-of-flight/mass spectrometer (TOF/MS) and the other going directly into the PID. This allowed for the comparison of the detector results of the PID with the TOF/MS. The oven was programmed to run at $40^{\circ} \mathrm{C}$ for $3 \mathrm{~min}$, then ramp at $15^{\circ} \mathrm{C} \mathrm{min}^{-1}$ to $125^{\circ} \mathrm{C}$, then at $20^{\circ} \mathrm{C} \mathrm{m^{-1 }}$ to $250^{\circ} \mathrm{C}$ and held for 5 minutes. Figure 4 shows how a capillary column is connected to the PID.

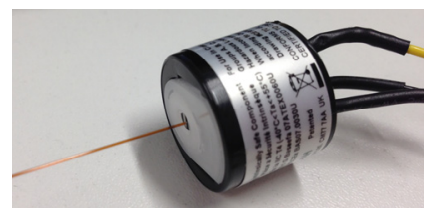

Figure 4: Capillary column connected to a PID.

A standard mixture including $4 \mathrm{nmol} / \mathrm{mol}$ (molar ppb) of benzene, 2,2,4trimethylpentane, heptane, toluene, octane, ethylbenzene, m-xylene, p-xylene, oxylene, 1,3,5-trimethylbenzene, 1,2,4-trimethylbenzene and 1,2,3trimethylbenzene was introduced into a thermal desorption unit (Markes Unity Series 2 Thermal Desorption Unit) prior to separation on the GC column. $1000 \mathrm{ml}$ of gas was sampled at $100 \mathrm{ml} / \mathrm{min}$. The trap was purged for 1 minute at $100 \mathrm{ml} / \mathrm{min}$ and heated from $-30^{\circ} \mathrm{C}$ to $300^{\circ} \mathrm{C}$ at the maximum heating rate of the system and held for 3 minutes.

The results for detection with TOF/MS and PID are shown in Figures 5 and 6 respectively. The results obtained with the PID shows good separation between the components with symmetrical peak shape comparable to that obtained with TOF/MS. The high PID response of the compounds gave a good signal to noise ratio. This PID chromatogram was generated with approximately $6.5-10 \mathrm{ng}$ of each compound. Peak skew is less than 1.8 for all peaks (with half of them less than 1.2) which we considered acceptable. The chromatogram indicates around 67000 theoretical plates as measured for toluene. It is worth noting that this PID result was achieved without any direct heating of the PID itself.

A second gas mixture containing approximately $26 \mathrm{ppb}$ of isoprene and $77 \mathrm{ppb}$ toluene was introduced separately. Parameters of the set up were identical to those used previously, but in this case only $100 \mathrm{~mL}$ of gas was sampled at $100 \mathrm{~mL}$ $\min ^{-1}$.

The results for detection with TOF/MS and PID are shown in Figures 7 and 8 respectively. The results obtained with the PID shows symmetrical peak shape comparable to that obtained with TOF/MS. The high relative PID response of the compounds resulted in a good signal to noise at the ppb level. The PID chromatogram was generated with approximately $3.69 \mathrm{ng}$ of isoprene and 14.78 $\mathrm{ng}$ of toluene at detector. Peak skew is around 1.0 for both compounds, with 68000 theoretical plates as measured for toluene. 


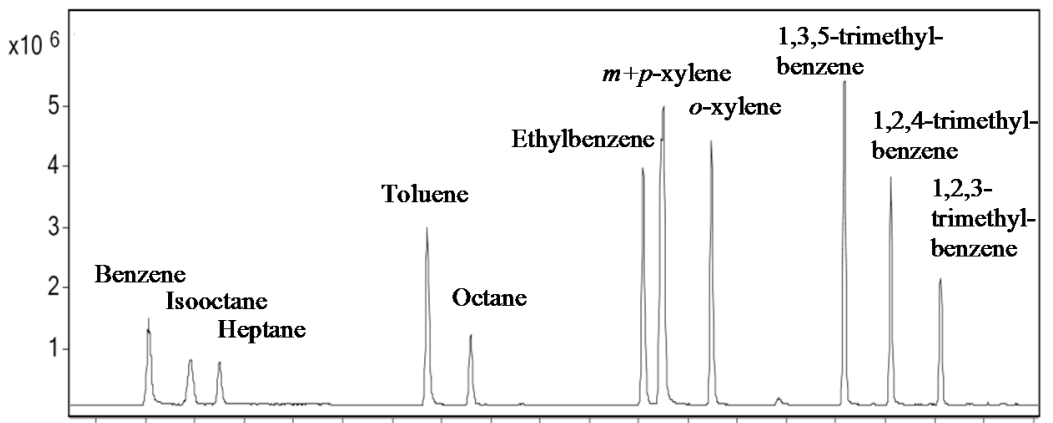

320340360380400420440460480500520540560580600620640660680 Counts vs. Acquisition Time (sec)

Figure 5: Separation of the 4 ppb standard gas mixture and detection by laboratory standard TOF/MS detector.

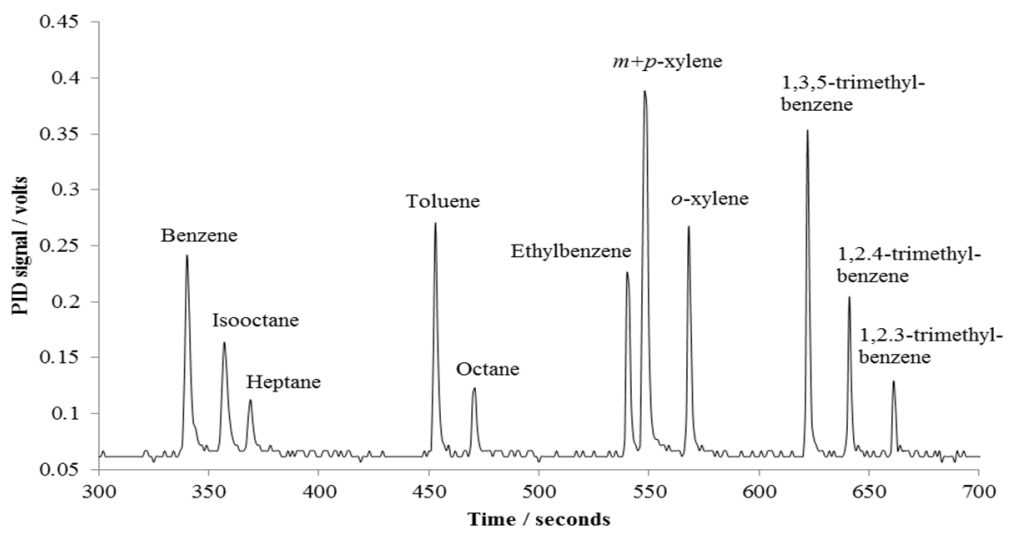

Figure 6: Separation of the 4 ppb standard gas mixture and detection by lowpower low-cost PID.

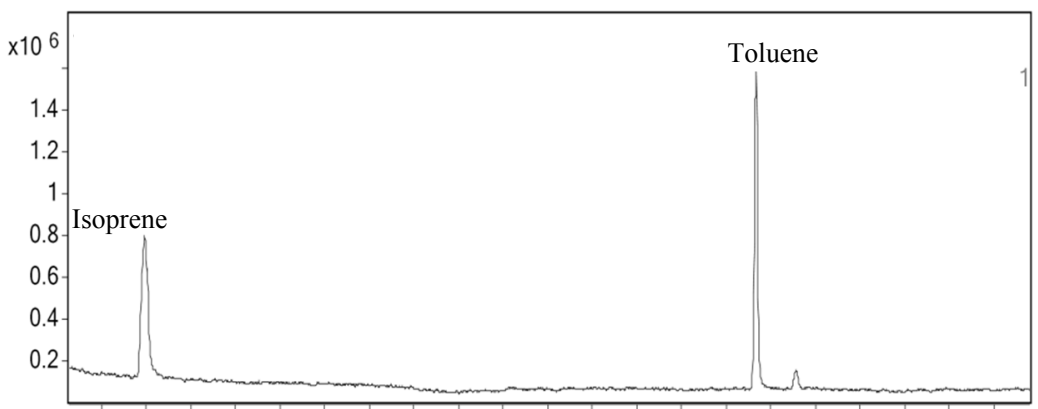

160180200220240260280300320340360380400420440460480500520540560 Counts vs. Acquisition Time (sec)

Figure 7: Separation of the isoprene and toluene gas mixture and detection by TOF/MS. 


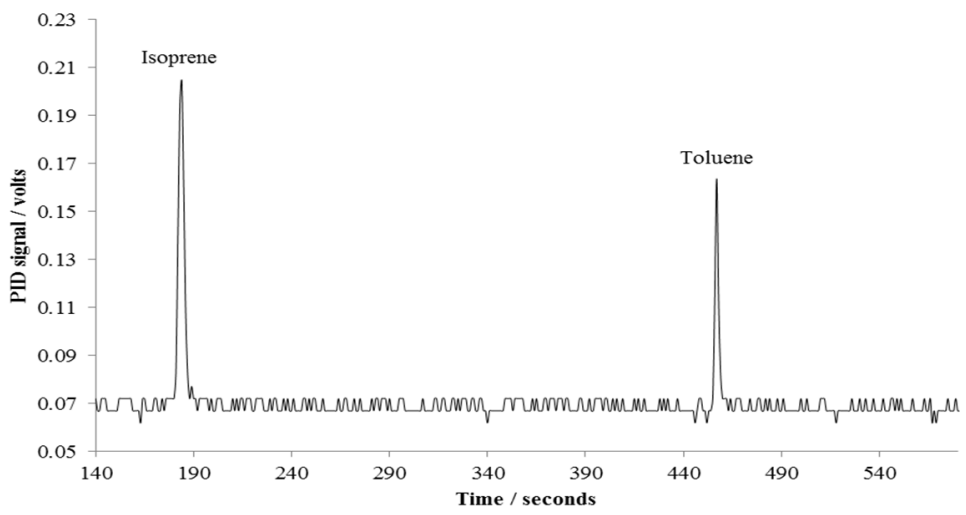

Figure 8: Separation of the isoprene and toluene gas mixture and detection by low-power PID.

From the data obtained using the PID, digital noise could be observed at the baseline of the chromatograms (see Figure 8). The current analogue-to-digital converter (A/D) has a resolution of 12 bit. To improve the resolution of the data capture, future systems will use an A/D with a higher resolution of 20 bit.

\section{Conclusions}

We have made important progress in the development of the subcomponents needed for a cost power and low cost VOC device. The GC-LOC will take a squarish spiral design to fit standard off-the-shelf Peltier devices that are available commercially. PDMS is considered a good material of choice because of its low manufacturing cost and ease of fabrication, although considerable testing work remains to be completed.

The use of a Peltier device to control the temperature of a $\mathrm{GC}$ column removes the dependence on the bulky and power hungry GC oven. We achieve precise control of the temperature set points and gradients of a Peltier based system through Proportional Integral Derivative control. A Peltier device with switchable polarities allows the initial temperature of the column to be as low as $10^{\circ} \mathrm{C}$, offering substantial advantages of the analysis of VOCs without the need for cryogenic cooling in standard GC ovens.

PID was chosen as the detector in this work as it offers substantial potential for the development of a field portable air quality sensor. When paired with a commercial GC system, the peaks produced by the PID were comparable to those produced by the TOF-MS, with acceptable peak skews and theoretical plates of $>65000$ for toluene. Peak tailing was observed to be minimal. These experiments highlighted the need for relatively high resolution data capture in order to fully exploit the inherent sensitivity of the PID. The ability to control the temperature of the chip with a low power function, and good evidence for the PID performance in producing peaks comparable to that of a TOF-MS, allows us to proceed to GC column testing and integration to produce a complete functional system. 


\section{References}

[1] Directive 2004/42/CE of the European Parliament and of the Council of 21 April 2004 on the limitation of emissions of volatile organic compounds due to the use of organic solvents in certain paints and varnishes and vehicle refinishing products, EUR-Lex: European Union Publications Office, http://eur-lex.europa.eu/legal-content/EN/TXT/?uri=CELEX:32004L0042.

[2] Environment Canada - Pollution and Waste - Volatile Organic Compounds - Background Government of Canada, https://www.ec.gc.ca/cov-voc/ default.asp?lang=En\&n=59828567-1.

[3] Palli, D., Saieva, C., Grechi, D., Masala, G., Zanna, I. \& Barbaro, A., DNA bulky adducts in a Mediterranean population correlate with environmental ozone concentration, an indicator of photochemical smog. International Journal of Cancer, 109(1), pp. 17-23, 2004.

[4] Pang, X. \& Lewis, A.C. A microfluidic lab-on-chip derivatisation technique for the measurement of gas phase formaldehyde. Analytical Methods, 4(7), pp. 2013-2020, 2012.

[5] Jacobson, M.Z., Atmospheric Pollution: History, Science and Regulation, Cambridge, United Kingdom: Cambridge University Press, 2002.

[6] Edwards, S.J., Lewis, A.C., Andrews, S.J., Lidster, R.T., Hamilton, J.F. \& Rhodes, C.N., A compact comprehensive two-dimensional gas chromatography $(\mathrm{GC} \times \mathrm{GC})$ approach for the analysis of biogenic VOCs. Analytical Methods, 5(1), pp. 141-150, 2013.

[7] de Gouw, J. \& Warneke, C., Measurements of volatile organic compounds in the earth's atmosphere using proton-transfer-reaction mass spectrometry. Mass spectrometry reviews, 26(2), pp. 223-257, 2006.

[8] Black, R.M., Clarke, R.J., Cooper, D.B., Read, R.W. \& Utley, D., Application of headspace analysis, solvent extraction, thermal desorption and gas chromatography - mass spectrometry to the analysis of chemical warfare samples containing sulphur mustard and related compounds. Journal of Chromatography A, 637(1), pp. 71-80, 1993.

[9] Robbat, A., Liu, T.Y. \& Abraham, B.M., On-site detection of polycyclic aromatic hydrocarbons in contaminated soils by thermal desorption gas chromatography/mass spectrometry. Analytical Chemistry, 64(13), pp. 1477-1483, 1992.

[10] Ochiai, N., Sasamoto, K., Kanda, H., Yamagami, T., David, F. \& Tienpont, B., Optimization of a multi-residue screening method for the determination of 85 pesticides in selected food matrices by stir bar sorptive extraction and thermal desorption GC-MS. Journal of Separation Science, 28(9-10), pp. 1083-1092, 2005.

[11] Sandra, P., Tienpont, B. \& David, F., Multi-residue screening of pesticides in vegetables, fruits and baby food by stir bar sorptive extraction-thermal desorption-capillary gas chromatography-mass spectrometry. Journal of Chromatography A, 1000(1-2), pp. 299-309, 2003.

[12] Ochiai, N., Sasamoto, K., Takino, M., Yamashita, S., Daishima, S. \& Heiden, A., Determination of trace amounts of off-flavor compounds in 
drinking water by stir bar sorptive extraction and thermal desorption GCMS. The Analyst, 126(10), pp. 1652-1657, 2001.

[13] Ochiai, N., Sasamoto, K., Takino, M., Yamashita, S., Daishima, S. \& Heiden, A., Simultaneous determination of preservatives in beverages, vinegar, aqueous sauces, and quasi-drug drinks by stir-bar sorptive extraction (SBSE) and thermal desorption GC-MS. Analytical and bioanalytical chemistry, 373(1-2), pp. 56-63, 2002.

[14] Wu, C.H., Feng, C.T., Lo, Y.S., Lin, T.Y. \& Lo, J.G., Determination of volatile organic compounds in workplace air by multisorbent adsorption/thermal desorption-GC/MS. Chemosphere. 56(1), pp. 71-80, 2004.

[15] Waterman, D., Horsfield, B., Leistner, F., Hall, K. \& Smith, S., Quantification of Polycyclic Aromatic Hydrocarbons in the NIST Standard Reference Material (SRM1649A) Urban Dust Using Thermal Desorption GC/MS. Analytical Chemistry, 72(15), pp. 3563-3567, 2000.

[16] Zhu, J. \& Aikawa, B., Determination of aniline and related mono-aromatic amines in indoor air in selected Canadian residences by a modified thermal desorption GC/MS method. Environment International, 30(2), pp. 135-143, 2004.

[17] Draeger. Draeger-Tubes \& CMS Handbook: Handbook for short term measurements in soil, water and air investigations as well as technical gas analysis, 16th Edition, Luebeck: Draeger Safety AG \& Co KGaA, 2011. http://www.nafeco.com/resources/pdfs/Draeger\%20Tubes\%20and\%20CM S\%20Handbook.pdf.

[18] Fine, G.F., Cavanagh, L.M., Afonja, A. \& Binions, R. Metal oxide semiconductor gas sensors in environmental monitoring. Sensors, 10(6), pp. $5469-5502,2010$.

[19] Halliday, J., Lewis, A.C., Hamilton, J.F., Rhodes, C., Bartle, K.D. \& Homewood, P., Lab-on-a-Chip GC for Environmental Research. LC-GC EUROPE. 23, pp. 514-523, 2010. 